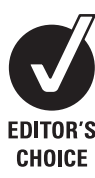

Bradford Neonatology, Bradford Royal Infirmary, Bradford, UK

Correspondence to:

S Oddie, Bradford Neonatology, Ward M1, Bradford Royal

Infirmary, Duckworth Lane,

Bradford BD9 6RJ, UK; Sam.

oddie@bradfordhospitals.nhs.uk

Accepted 23 April 2008

Published Online First 7 May 2008

\title{
The value of the postnatal examination in improving child health
}

\author{
K Green, S Oddie
}

\section{ABSTRACT}

This paper reviews the evidence regarding whether a standardised examination in the newborn period can improve infant health. The review considers aspects of delivering such a service from timing and number of examinations through to who should perform examinations, and whether evidence supports current practice. Infants at higher risk of anomaly such as those born preterm are highlighted. Aspects of the examination itself are reviewed, such as detection of congenital heart disease, and the relatively poor detection rate which does not seem to be improving. Potential advantages of additional screening with pulse oximetry are covered. The paper also discusses screening for developmental dysplasia of the hip, which the UK national screening council is unsure of the benefit of, the difficulties of detecting all cases of cleft palate and problems with screening for the very important congenital cataract. The authors draw attention to the relative rarity of some conditions and reflected on how this complicates screening.

That babies are examined in the immediate newborn period is "universally accepted as good practice" and mandated in recent national guidance. ${ }^{2}$ Here, we have reviewed the literature pertaining to the effectiveness of this examination. First, we present the evidence regarding the process of the neonatal examination, second, we review some of the more important constituent parts of the examination, and finally we address the question whether the newborn examination provides a health improvement or just gives false reassurance.

\section{NUMBER OF EXAMINATIONS}

Twelve per cent of delivery units reportedly plan two examinations prior to discharge. ${ }^{3}$ A group from Aberdeen examined whether two examinations were better than one. ${ }^{4}$ This rare randomised controlled trial in the field of health promotion was sadly, but unsurprisingly, not powered to show effects on outcomes of greatest interest to the neonatologist, namely infant death or early detection of serious anomaly. Almost 10000 babies were studied and no difference in rates of actual rather than suspected anomalies was noted, although the repeated examination resulted in more hip dysplasia being suspected. If anything, this study should reinforce an intention to do one examination well rather than aiming to do two on all babies.

Are there groups of babies in whom a second examination might be useful? Preterm infants are twice as likely as term infants to have congenital heart disease, ${ }^{5}$ and preterm infants and those born small for gestational age are three times more likely to have congenital cataract than those born at term. ${ }^{6}$ Thus careful, repeated clinical examination of all infants born significantly preterm, or those term babies who are initially unwell is appropriate prior to hospital discharge.

\section{TIMING OF SCREENING EXAMINATION}

Most, though not all, neonatal services in the UK aim to deliver a structured examination to all babies prior to hospital discharge. A few UK units devolve as many as half of these examinations to primary care; it is unknown how many of these infants actually have an examination in primary care, or when it occurs. Such an approach may be increasingly difficult to defend. Thus for most services the timing of discharge dictates the timing of examination with most services preferring not to do examinations before $6 \mathrm{~h}$ of age. ${ }^{3}$

Arguably if only one examination is being performed, this should be after $24 \mathrm{~h}$ to allow maximal time for the ductus to close and pulmonary vascular resistance to start to fall, thus increasing the chances of revealing previously occult congenital heart disease. ${ }^{7}$ Paediatricians also hold that earlier examination may itself mandate earlier discharge, leading to congenital anomalies and feeding problems presenting in the community. ${ }^{8}$ Worryingly, those discharged earlier are typically more deprived and coincidentally at higher risk of anomaly. ${ }^{9-12}$ By contrast, earlier examination may allow abnormalities detected to be dealt with before symptoms develop and in a planned way without discharge being delayed.

As maternity stays shortened, initial reports appeared to confirm risks associated with early discharge, perhaps mediated by timing of last professional review. ${ }^{13}$ This effect was not shown in a UK population. ${ }^{12}$ However a much larger US study examined rates of readmission by diagnosis. Discharge on the day of birth was associated with a doubling in rates of readmission for obstructive cardiac defects and low bowel obstruction, ${ }^{14}$ although such readmissions were rare in themselves. We interpret these data to suggest that where discharge before $48 \mathrm{~h}$ is planned and examination is the sole screen for anomaly, it ought to be as late as practically achievable unless there are concerns about the baby.

\section{WHO SHOULD CONDUCT THE SCREENING EXAMINATION?}

Increasingly non-medical staff are training to perform newborn examinations - at least a third of units have an appropriately qualified midwife. 
However, in 2004 a third of these midwives were not doing examinations and overall only $2 \%$ of babies in England were examined by a midwife. ${ }^{3}$ Working time pressures on junior doctors and reducing postpartum stays are intensifying pressure for midwives and others to acquire these skills, and more babies are probably examined by midwives and others now. In addition, there is a widespread perception that midwives may do the examination at least as appropriately as, or more so than, junior doctors. ${ }^{3}$

Several studies have compared examination by non-medical staff with that by medical staff. ${ }^{3} 1516$ These studies have not been of sufficient size to measure true efficacy and have tended to look at process, referral rates, technical aspects and maternal satisfaction. The largest study, conducted in the UK, randomised 829 low-risk neonatal examinations to assessment by doctors or midwives. There were no suggestions that the quality of midwifery examination was lower, though quality of examination was questioned in both arms and there was poor agreement about what constituted good-quality physical examination. Mothers were more satisfied with a midwife rather than a trainee doctor performing the newborn examination, because midwives were more likely to discuss healthcare issues such as feeding, sleeping and skincare, and were able to provide continuity of care. The researchers showed that a midwifery examination took 5 min (50\%) longer. ${ }^{3}$

Further research, perhaps in the form of case-control studies comparing the professional background of initial examiners of infants with late presenting anomalies to those of controls, should be commissioned.

\section{DETECTING CONGENITAL HEART DISEASE}

Careful assessment can reveal birth prevalences of congenital cardiovascular anomalies well above 10/1000 livebirths, in contrast with the more usually quoted $5-8 / 1000$. The excess is mostly small ventricular septal defects. ${ }^{717}{ }^{18}$ Defects whose early detection would make a dramatic difference to babies outcome occur very rarely (see table 1 ) with individuals and even units having limited exposure to each condition. With such rarity it is more practical to model detection strategies than to test them in clinical studies.

Cyanosis in the newborn is difficult to detect at clinically important levels, ${ }^{20}$ murmurs may be missed or over diagnosed and femoral pulses are challenging to assess. Together with early discharge and failure to assess infants identified as at risk, these real-life limitations to clinical examination may underlie the 1994 report that $30 \%$ of congenital cardiac disease deaths were undiagnosed until postmortem examination ${ }^{21}$ and that in

Table 1 Congenital heart disease where considerable improvement in prognosis might be expected if positive early diagnoses reached

\begin{tabular}{lll}
\hline & $\begin{array}{l}\text { Prevalence per } \\
\mathbf{1 0 0 ~ 0 0 0 ~ l i v e b i r t h s ~}\end{array}$ & $\begin{array}{l}\text { Cases/10 years in infants } \\
\text { born at hospital delivering } \\
\mathbf{5 0 0 0} \text { infants each year }\end{array}$ \\
\hline Aortic stenosis & 20 & 10 \\
Coarctation of the aorta & 35 & 18 \\
Hypoplastic left heart & 14 & 7 \\
Interruption of the aortic arch & 8 & 4 \\
Pulmonary atresia & 21 & 11 \\
Transposition of the great & 30 & 15 \\
arteries & & 5 \\
Total anomalous pulmonary & 9 & \\
venous connection & &
\end{tabular}

Table modified from data summarised in Knowles et al. ${ }^{19}$
$65 \%$ of infants with congenital heart disease, it was missed at newborn examination. ${ }^{22}$

Data from a single UK centre (1996-2004) seem to show that detection rates following the newborn examination have vastly improved with 150/176 infants with congenital heart disease detected in the first year suspected prior to discharge. ${ }^{7}$ By contrast in a 20 -year study in an area including that single centre, rates of early diagnosis have remained disappointingly static, though with a reduction in cases diagnosed only at postmortem. ${ }^{23}$ This may reflect the competing effects of faster investigation and more easily accessed echocardiography, and shortening maternity stays. For example in Scotland mean length of maternity stay has reduced by $30 \%$ over 10 years to $2000^{24}$ and this clearly will have reduced opportunities for in hospital presentation of duct-dependent congenital heart disease.

Knowles et $a l^{19}$ reviewed data, substantially from the Northern Region of the UK (1980-1994), and expert opinion on timing, nature of diagnoses and impact of screening to establish a decision analytic model. The model estimates how many children with life-threatening cardiac diagnoses are likely to be diagnosed as a result of screening examinations currently and with other approaches. Their work suggests that just 122 infants for every 100000 screened has life-threatening cardiac disease undetected at the time of the screening examination, and that just 39 of these will be picked up by examination alone. This number could be doubled by the addition of either universal echocardiography or, more realistically, pulse oximetry screening. The introduction of additional oximetry screening could achieve these benefits at the relatively small cost of $£ 4900$ per timely diagnosis achieved (leaving aside the cost improvements associated with the probability that diagnosis before collapse improves biological outcome).

Such screening would come with associated false positives. Screening echocardiography would result in a false-positive rate of $5.4 \%$, while clinical examination alone results in just $0.5 \%$ in this model. Adding oximetry to examination raises the falsepositive rate to $1.3 \%$.

Comparable benefits to additional oximetry were modelled when all "clinically important" (425 cases/100 000 livebirths undetected at time of examination) diagnoses were also included with a rise in the detection rate at $24 \mathrm{~h}$ from $32 \%$ to $50 \%$. These more numerous defects are not insignificant, not least to families. In associated focus group work, families described the conventional screen as "outdated", "prewar" and carried out too quickly.

Because some infants in the model have presented prior to "screening", the authors model the impact of examinations at 0 and $48 \mathrm{~h}$. Although the tests perform with similar overall predictive value whenever they are done, more early diagnoses can be reached if the examinations are done earlier, as fewer true cases will remain asymptomatic. Oximetry continues to add a marked benefit over clinical examination alone regardless of timing, though the model assumes timing would be simultaneous.

Furthermore, current evidence suggests that antenatal detection of cardiac anomalies remains poor ${ }^{25}$ although it may be improving in the relevant group of life-threatening anomalies. ${ }^{24}$ With improvements in ultrasound technology, such as the introduction of three-dimensional ultrasound, and perhaps their widespread usage, it is plausible that antenatal detection rates might improve from their recent $20 \%$ detection rate. ${ }^{24}$ Even if antenatal detection rates, across whole populations, of 
life-threatening anomalies reach the heights of $90 \%$, the model suggests benefits would be retained at a cost-effective level.

What is the clinician to make of these analyses? The modelling further bolsters the established place of oximetry in the assessment of a newborn with a murmur, but what is the place of oximetry screening? The Pulse Ox observational study ${ }^{26}$ will tell us, but where this attractive practice is adopted elsewhere, we must measure its impact. Questions may remain about whether a single lower limb measurement is inferior to comparing preductal and postductal saturations, and the optimal timing of oximetry.

More uncertainty surrounds the management of infants with murmurs. While these occur in $0.5-1.9 \%$ of well babies, only around $40 \%$ of such infants will have congenital heart disease. ${ }^{27}$ The challenge for clinicians is to rapidly get to a diagnosis while worrying the parents enough to seek medical review if appropriate without causing destructive anxiety.

Access to echocardiography is widening, but it is still a limited resource in most areas. A staged approach, with initially clinical review, and early echocardiography for those with persisting murmurs, such as that described in Ashington may be optimal. ${ }^{7}$ Although this paper reported low levels of anxiety, work in newborn hearing screening suggests that minimising repeated reviews before a final diagnosis is reached or excluded reduces parental anxiety. ${ }^{28-30}$ Other work in a paediatric cardiology setting provides some evidential backing for the idea that good quality initial explanations may reduce the anxiety implicit in any repeated review. ${ }^{31}$

\section{DEVELOPMENTAL DYSPLASIA OF THE HIP}

The true birth prevalence of developmental dysplasia of the hip $(\mathrm{DDH})$ is unknown, but has been reported as varying between 1.5/1000 and 20/1000 livebirths. ${ }^{32-34}$ Traditional screening, to reduce late presentation, ${ }^{35}$ involves the physical examination of the hips and lower limbs including the Barlow and Ortolani manoeuvres. The sensitivity of this screening test varies depending on the skill and experience of the examiner and ranges of 0.74 to 0.99 have been reported. ${ }^{33}$ The test appears to be practised variably and inconsistently. For example, in videoed examinations as part of a trial, the Barlow test was not seen in many examinations and there was poor agreement about adequate examination, despite training of examiners and assessors. $^{36}$

Ultrasound screening of hips in addition to physical examination is now well established although opinion is divided among supporters of universal and selective screening. (See Shipman $e^{2} a^{37}$ for a comprehensive review.) The assumption underlying much of the original research in this area is that early detection of $\mathrm{DDH}$ makes a difference to outcome, either through non-surgical or surgical intervention. The most common non-surgical intervention is the Pavlik harness which is replacing other rigid-splint treatments. It has the advantages of being much more comfortable for babies and makes infant care easier for families. However, as more than $80 \%$ of clinically unstable hips noted at birth have been shown to resolve spontaneously, ${ }^{37}$ it is difficult to assess the impact of such (usually non-surgical) treatment measures. Practitioners are also mindful of the complications of treatment. For example, avascular necrosis of the femoral head due to using a Pavlik harness has an incidence ranging from $0 \%$ to $28 \%{ }^{38}$ It remains unclear whether the changes in surgical interventions before and after the implementation of screening programmes truly reflect a screening programme that is improving infant health. ${ }^{37}$ While the programme continues it is logical to have a policy based on trained screeners, organised referral and recognised risk factors for supplementary ultrasound screening. Recognised risk factors include:

- breech presentation

- family history of DDH

- structural foot deformity

- hip "click"*

- any recognised clinical sign of DDH.

*Debate continues about the significance of a click in an otherwise stable hip; however a proportion of such hips (1.5$4 \%$ ) will have a significant abnormality when imaged by ultrasound, so referral is recommended. ${ }^{39}$

\section{CONGENITAL CATARACT}

Congenital cataracts are the leading cause of preventable childhood partial sight or blindness, ${ }^{40}{ }^{41}$ which led to screening by seeking a "red reflex". Also, recent advances in anaesthesia, surgical techniques and contact lenses have combined to make neonatal cataract surgery safer and subsequent visual rehabilitation more successful. ${ }^{40}$ The optimal time to remove a dense congenital cataract in an infant and initiate optical treatment appears to be $4-6$ weeks of age. ${ }^{42}$ Early removal risks the eye developing aphakic glaucoma, whereas later surgery compromises the visual outcome..$^{42}$ Screening for cataracts is effective in terms of improving visual outcome. Half of all children treated for bilateral disease will achieve a level of acuity (6/18) that is conventionally considered the threshold for mainstream schooling, using printed media and requiring only minimal extra help. ${ }^{43}$

Not all cataracts of "congenital" origin are identified by newborn examination. One study suggested the pickup rate was as low as $35 \%{ }^{44}$ This perhaps reflects its rarity at about $3 /$ 10000 children, ${ }^{45}$ which means a large district general hospital would see three children in 2 years if all were detected. With attention to training using appropriate images and routine review of technique, along with streamlined referral pathways, continuous improvements in ascertainment can probably be achieved. However, it is unlikely that this test will ever be $100 \%$ sensitive.

The UK National Screening Committee suggests that all babies with a family history of inherited eye disease should be referred to an ophthalmologist. It also suggests children with major neurodevelopmental disorders should be reviewed by an ophthalmologist and orthoptist, and those with other neurodevelopmental disorders, particularly hearing loss, should have an expert eye examination as a matter of routine. ${ }^{46}$ There is no attempt to define what an "expert eye opinion" should constitute, nor indeed what constitutes a relevant neurodevelopmental disorder. Although these recommendations seem logical, there are considerable implications for professional training, resource allocation and service organisation nationally and locally, and require further research and debate. ${ }^{46}$

\section{CLEFT LIP AND PALATE}

A cleft lip and/or palate is the fourth most common congenital birth defect ${ }^{47}$ with a UK birth prevalence of 1 in $700 .{ }^{48}$ A cleft lip is obvious to everyone the minute the baby is born, but there is a recognised delay in detecting an isolated cleft palate with between $28 \%$ and $31 \%$ not being detected on day 1 of life. ${ }^{48} 49$ Early diagnosis is obviously optimal, so newborn infants are routinely examined for the presence of a cleft palate. However, this examination does not begin to meet the criteria for a good screening test. First, whether occasional delays in diagnosis have 
any long-term implication beyond its effect on parental confidence in doctors is uncertain. Second, most present prior to formal examination with milk emerging from the nose during feeds.

It is strongly recommended that examination of the newborn infant for a possible cleft palate should include inspection under direct vision. ${ }^{48}{ }^{49}$ Palpation alone is not enough ${ }^{50}$ as unless the posterior palatal spines can be felt (which if easily felt, rule out the presence of a cleft palate ${ }^{48}$ ) palpation for the cleft itself is a notoriously inaccurate technique. Inspection under direct vision is difficult without assistance and not universally practised. Using a sterile $1 \mathrm{ml}$ syringe to depress the tongue to visualise the posterior palate may be helpful where a baby does not cry. ${ }^{48}$ An assistant may also enable the examiner to examine the whole palate without difficulty. ${ }^{49}$

Examination with a laryngoscope is recommended ${ }^{50}$ if there are any risk factors such as:

- family history

- teratogen exposure

- other dysmorphic features

- baby has feeding difficulties/nasal regurgitation

- other clinical suspicion.

\section{IS NEWBORN EXAMINATION REALLY A "SCREENING EXAMINATION"?}

Having reviewed the available evidence, we are left with the question of whether the newborn examination really is a "screening examination", as is suggested by the recent National Institute for Health and Clinical Excellence (NICE) recommendations. ${ }^{2}$ We note that the NICE postnatal care guideline is based on a detailed systematic review of the evidence-for example, the section on management of postpartum headache. However, the section on newborn examination is based only on standard texts.

Wilson and Junger's criteria, for identifying tests as appropriate for use in screening, are well known, though expanded and restated by the UK National Screening Committee (table 2). ${ }^{51}$

Biochemical screening of newborns for congenital hypothyroidism, phenylketonuria and more recently cystic fibrosis do seem to satisfy these criteria. Conditions such as asymptomatic left heart outflow obstruction or congenital cataract would also appear to be good candidates for screening with their

Table 2 UK National Screening Committee criteria for appraising screening programmes

\begin{tabular}{|c|c|}
\hline \multirow[t]{3}{*}{ Condition } & Important health problem \\
\hline & $\begin{array}{l}\text { Well-understood natural history with either latent period, or early } \\
\text { symptomatic stage }\end{array}$ \\
\hline & Practicable primary prevention implemented \\
\hline \multirow[t]{2}{*}{ Test } & Simple, safe, precise, acceptable validated test \\
\hline & Agreed policy on investigation of screen positives \\
\hline \multirow[t]{2}{*}{ Treatment } & $\begin{array}{l}\text { Evidence of benefit for screening identified cases over symptomatic } \\
\text { cases through effective treatment }\end{array}$ \\
\hline & Management of disease before screening should be optimised \\
\hline \multirow[t]{6}{*}{ Programme } & $\begin{array}{l}\text { Randomised controlled trial evidence that programme is effective in } \\
\text { reducing mortality or morbidity }\end{array}$ \\
\hline & Acceptable to public \\
\hline & Value for money \\
\hline & Agreed plan for monitoring, management and quality assurance \\
\hline & Adequately staffing and facilities \\
\hline & Appropriate patient information available \\
\hline
\end{tabular}

Adapted from the UK National Screening Committee criteria for screening programmes. presymptomatic phase, reasonably clear case definition, and accepted and effective treatment.

It is true that examination-based screening for congenital heart disease has not been shown to work well in practice (see above). In addition, the natural history of "congenital cataract" may be such that even expert examination in the immediate newborn period may not identify all true cases. ${ }^{45} 4852$ Furthermore, the view of the UK National Screening Committee is that if the introduction of screening for developmental dysplasia of the hip were considered now it "would probably not be accepted", were it not that "it is so ingrained ... [that] it would be almost impossible to stop unless overwhelming evidence of ineffectiveness could be obtained". ${ }^{53}$

More recently adopted programmes, such as universal hearing screening, are better evidenced, audited and resourced than historically implemented programmes, such as screening for congenital heart disease. ${ }^{54}$

\section{VALUE OF SCREENING EXAMINATION IN DETECTING NON- TARGET CONDITIONS}

Ill children may present at screening examination, even if parents have not noted symptoms and signs. When examinations were predominantly carried out within $24 \mathrm{~h}, 0.3 \%$ of all infants had notable acute pathology identified by clinical examination, in some cases supplemented by saturation screening. ${ }^{27}$ Less acute pathology, such as jaundice, is also frequently noted at routine examination. While universal checking of a predischarge bilirubin is far from being routine practice in the UK, many of these infants will benefit from a clinical judgement about the utility of such a measurement. ${ }^{55}$

A wide variety of minor developmental anomalies and injuries may be detected in as many as $15 \%$ of babies during a good newborn examination, ${ }^{56}$ not including erythema toxicum and "stork bite" birthmarks. Although minor, a clear diagnosis and explanation to families is important, which may underlie why examinations where more time is taken leave parents more satisfied. ${ }^{3}$

Finally, the newborn examination is also an opportunity to review if specific targeted screening, or even treatment, is indicated. Commonly postnatal imaging is required to elucidate findings from prenatal imaging, while more rarely infants may be at risk of serious metabolic or infectious disease on the basis of family history. Sadly clinical practice and the available evidence show that family history is poorly ascertained at newborn examination. For this reason many units have systems to prearrange such management even before delivery.

\section{CONCLUSION}

Examination in the first days of life is highly valued by professionals and public alike although it is an imperfect "screen". A single examination, by a trained examiner, at the time of discharge using conventional techniques probably enhances the health of some infants quite significantly. Supplementary screening, for example with oximetry, may be justified.

\section{Competing interests: None.}

\section{REFERENCES}

1. Physical examination. In: Hall DM, Elliman D, eds. Health for all children. Oxford: Oxford University Press, 2003.

2. Demott K, Bick D, Norman R, eds. Clinical guidelines and evidence review for post natal care: routine post natal care of recently delivered women and their babies. London: National Collaborating Centre for Primary Care and Royal College of General Practitioners, 2006. 
3. Townsend J, Wolke D, Hayes J, et al. Routine examination of the newborn: the EMREN study. Evaluation of an extension of the midwife role including a randomised controlled trial of appropriately trained midwives and paediatric senior house officers. Health Technol Assess 2004:8: iii-iv, ix-xi, 1-100.

4. Glazener CM, Ramsay CR, Campbell MK, et al. Neonatal examination and screening trial (NEST): a randomised, controlled, switchback trial of alternative policies for low risk infants [see comment]. BMJ 1999:318:627-31.

5. Tanner K, Sabrine N, Wren C. Cardiovascular malformations among preterm infants. Pediatrics 2005;116:e833-8.

6. SanGiovanni JP, Chew EY, Reed GF, et al. Infantile cataract in the collaborative perinatal project: prevalence and risk factors. Arch Ophthalmol 2002;120:1559-65.

7. Patton C, Hey E. How effectively can clinical examination pick up congenital heart disease at birth? Arch Dis Child Fetal Neonatal Ed 2006;91:F263-7.

8. Lock M, Ray JG. Higher neonatal morbidity after routine early hospital discharge: are we sending newborns home too early? CMAJ 1999;161:249-53.

9. Vrijheid M, Dolk H, Stone D, et al. Socioeconomic inequalities in risk of congenital anomaly. Arch Dis Child 2000;82:349-52.

10. Neasham D, Dolk H, Vrijheid M, et al. Stillbirth and neonatal mortality due to congenital anomalies: temporal trends and variation by small area deprivation scores in England and Wales, 1986-96. Paediatr Perinat Epidemiol 2001;15:364-73.

11. Galbraith AA, Egerter SA, Marchi KS, et al. Newborn early discharge revisited: are California newborns receiving recommended postnatal services? Pediatrics 2003;111:364-71.

12. Oddie SJ, Hammal D, Richmond S, et al. Early discharge and readmission to hospital in the first month of life in the Northern Region of the UK during 1998: a case cohort study [see comment]. Arch Dis Child 2005;90:119-24.

13. Charles S, Prystowsky B. Early discharge, in the end: maternal abuse, child neglect, and physician harassment. Pediatrics 1995;96(4 Pt 1):746-7.

14. Danilesen B, Castles AG, Damberg CL, et al. Newborn discharge timing and readmissions: California 1992-1995. Pediatrics 2000:106:34-9.

15. Lee TW, Skelton RE, Skene C. Routine neonatal examination: effectiveness of trainee paediatrician compared with advanced neonatal nurse practitioner. Arch Dis Child Fetal Neonatal Ed 2001;85:F100-4

16. Rowley MJ, Hensley MJ, Brinsmead MW, et al. Continuity of care by a midwife team versus routine care during pregnancy and birth: a randomised trial. Med J Aust 1995;163:289-93.

17. Wren C, Richmond S, Donaldson L. Temporal variability in birth prevalence of cardiovascular malformations. Heart 2000:83:414-19.

18. Hoffman JIE, Kaplan S. The incidence of congenital heart disease. J Am Coll Cardiol 2002;39:1890-900.

19. Knowles R, Griebsch I, Dezateux C, et al. Newborn screening for congenital heart defects: a systematic review and cost-effectiveness analysis. Health Technol Assess 2005:9.

20. O'Donnell C, Kamlin 0, Davis P, et al. Clinical assessment of infant colour at delivery. Arch Dis Child Fetal Neonatal Ed 2007;92:465-7.

21. Abu-Harb M, Wyllie J, Hey E, et al. Presentation of obstructive left heart malformations in infancy. Arch Dis Child Fetal Neonatal Ed 1994;71:F179-83.

22. Wren C, Richmond S, Donaldson L. Presentation of congenital heart disease in infancy: implications for routine examination. Arch Dis Child Fetal Neonatal Ed 1999;80:F49-53

23. Wren C, Reinhardt Z, Khawaja K. Twenty-year trends in diagnosis of life-threatening neonatal cardiovascular malformations. Arch Dis Child Fetal Neonatal Ed 2008; 93 :F33-5

24. ISD Scotland. Scottish health statistics 2000. Section M2: maternity and neonatal. http://www.isdscotland.org/isd/files/M2 2000.pdf (accessed 8 Jan 2008).

25. Bricker L, Garcia J, Henderson J, et al. Ultrasound screening in pregnancy: systematic review of the clinical effectiveness, cost-effectiveness and women's views. Health Technol Assess 4:i-vi.

26. Pulse 0x. Pulse oximetry as a screening test for congenital heart disease in newborn babies. http://www.pulseox.bham.ac.uk (accessed 6 Jan 2008)

27. Richmond S, Wren C. Early diagnosis of congenital heart disease. Semin Neonatal 2001:6:27-35.

28. Clemens CJ, Davis SA, Bailey AR. The false-positive in universal newborn hearing screening. Pediatrics 2000;106:E7.

29. Owen M, Webb M, Evans K. Community based universal neonatal hearing screening by health visitors using otoacoustic emissions. Arch Dis Child Fetal Neonatal Ed 2001;84:F157-62.
30. Vohr BR, Letourneau KS, McDermott C. Maternal worry about neonatal hearing screening. J Perinatol 2001;21:15-20.

31. Giuffre RM, Walker I, Vaillancourt $S$, et al. Opening Pandora's box: parental anxiety and the assessment of childhood murmurs. Can J Cardiol 2002;18:406-14.

32. American Academy of Pediatrics. Committee on Quality Improvement, Subcommittee on Developmental Dysplasia of the Hip. Clinical practice guideline: early detection of developmental dysplasia of the hip. Pediatrics 2000;105/4 Pt 1):896-905.

33. Witt C. Detecting developmental dysplasia of the hip. Adv Neonatal Care 2003;3:6575.

34. Garvey M, Donoghue VB, Gorman WA, et al. Radiographic screening at four months of infants at risk for congenital hip dislocation [see comment]. J Bone Jt Surg [Br] 1992; 74:704-7.

35. Wirth T, Stratmann L, Hinrichs F. Evolution of late presenting developmental dysplasia of the hip and associated surgical procedures after 14 years of neonatal ultrasound screening. J Bone Joint Surg [Br] 2004;86-B:585-9.

36. Bloomfield L, Rogers C, Townsend J, et al. The quality of routine examinations of the newborn performed by midwives and SHOs; an evaluation using video recordings. J Med Screen 2003;10:176-80.

37. Shipman SA, Helfand M, Moyer VA, et al. Screening for developmental dysplasia of the hip: a systematic literature review for the US Preventive Services Task Force. Pediatrics 2006;117:e557-76.

38. Nakamura J, Kamegaya M, Saisu T, et al. Treatment for developmental dysplasia of the hip using the Pavlik harness: long-term results. J Bone Joint Surg [Br] 2007;89B:230-5.

39. Dinkevich $\mathbf{E}$, Hupert J. The well child. In: Moyer VA, ed. Evidence based paediatrics and child health, 2nd edn. Oxford: Blackwell BMJ Books, 2004:173-5.

40. Ruttum MS, Nelson DB, Wamser MJ, et al. Detection of congenital cataracts and other ocular media opacities. Pediatrics 1987:79:814-17.

41. Ward Platt MP. Newborn screening examination (excluding congenital dislocation of the hip). Semin Neonatol 1998;3:61-6.

42. Lambert SR. Treatment of congenital cataract [comment]. $\mathrm{Br} \mathrm{J}$ Ophthalmol 2004;88:854-5.

43. Chak M, Wade A, Rahi JS; British Congenital Cataract Interest Group. Long-term visual acuity and its predictors after surgery for congenital cataract: findings of the British congenital cataract study. Invest Ophthalmol Visual Sci 2006;47:4262-9.

44. Rahi JS, Dezateux C. National cross sectional study of detection of congenital and infantile cataract in the United Kingdom: role of childhood screening and surveillance. BMJ 1999;318:362-5

45. Rahi JS, Dezateux C, British Congenital Cataract Interest Group. Measuring and interpreting the incidence of congenital ocular anomalies: lessons from a national study of congenital cataract in the UK. Invest Ophthalmol Visual Sci 2001;42:1444-8.

46. Rahi JS, Williams C, Bedford H, et al. Screening and surveillance for ophthalmic disorders and visual deficits in children in the United Kingdom. $\mathrm{Br} J$ Ophthalmol 2001:85:257-60.

47. Merritt L. Part 2. Physical assessment of the infant with cleft lip and/or palate. Adv Neonatal Care 2005;5:125-34

48. Habel A, Elhadi N, Sommerlad B, et al. Delayed detection of cleft palate: an audit of newborn examination. Arch Dis Child 2006;91:238-40.

49. James CS, Todd PJ. Examination of the neonatal palate [electronic letter]. Arch Dis Child 2002:F210.

50. Armstrong H, Simpson RM. Examination of the neonatal palate. Arch Dis Child Fetal Neonatal Ed 2002;86:F210.

51. Criteria for appraising the viability, effectiveness and appropriateness of a screening programme: UK National Screening Committee, 2003. http://www.nsc.nhs.uk/pdfs/ Criteria.pdf (accessed 6 Jan 2008)

52. Rennie JM. Examination of the newborn. In: Rennie JM, ed. Roberton's textbook of neonatology, 4th edn. Elsevier, 2005:250.

53. Child Health Sub-Group Report. Dysplasia of the hip. September 2004. Search via: http://www.library.nhs.uk (accessed 6 Jan 2008)

54. Davis A, Bamford J, Wilson I, et al. A critical review of the role of neonatal hearing screening in the detection of congenital hearing impairment. Health Technol Assess 1997; 1:i-iv

55. Bhutani VK, Johnson L, Sivieri EM. Predictive ability of a predischarge hour-specific serum bilirubin for subsequent significant hyperbilirubinemia in healthy term and nearterm newborns [see comment]. Pediatrics 1999;103:6-14.

56. Preut D, Reiter HL, Klingmuller B. Abnormalities detected by the first routine newborn examination. Monatsschr Kinderheilkd 1996;144:1092-7. 